\title{
A Study on Teaching Reform of Economic Mathematics-Calculus in Financial and Economic Colleges and Universities
}

\author{
Tao Chen ${ }^{1}$ and Wenbin Liu ${ }^{1 *}$ \\ ${ }^{1}$ Deartment of Public Course, Wuhan Technology and Business University, \\ Wuhan 430065, China
}

( ${ }^{\star}$ Corresponding Author: Wenbin Liu, 812926096@qq.com)

Keywords: Calculus; Teaching reform; Economic mathematics

\begin{abstract}
Calculus, as a basic and instrumental subject of science and technology, is a pre-study course in other advanced mathematics. It is also the core content of students' study in school. As the basic course of economic mathematics in financial and economic colleges and universities, calculus is one of the core courses of these specialties. It is the basis for students to study related follow-up courses. It is not only an important carrier to cultivate the rational thinking quality and speculative ability of college students, but also an important means to develop the potential initiative and creativity of college students.
\end{abstract}

\section{Introduction}

The basic courses of economic mathematics generally include calculus, linear algebra and probability statistics. The second school year studies the linear algebra and the probability statistics. As the first course of economic mathematics that the freshman has come into contact with, it plays an important role in the whole two years' study of economic mathematics. The actual situation of integral teaching is not optimistic. However, the contents of the teaching are numerous, the teachers are constrained by the teaching plan and syllabus, they often hurry to catch up with the progress and are not easy to take care of the feelings of the students. The classroom teaching still follows the mode of teachers' lectures and students' listening to classes. Students did not become the main body of the teaching process, did not really integrate into the teaching process, students and teachers inverted the subject and object, which to a large extent reduced the interest of students in learning college mathematics. To some extent, the students' enthusiasm for learning has been dampened. It is an insurmountable basic role in the training of applied talents of economic management.

\section{The Present Situation Of Teaching}

In modern college education, students' self-study ability and interest in subjects are very important, but with the development of the times, students come from the Internet out of an environment full of temptation. The effects of various factors on high-tech products Some students have not grasped their attention and forgotten their responsibilities as students. Of course, this is also a great challenge to modern college education, especially the traditional basic education such as calculus.

The concept of modern teaching is backward, the theory is preferred, and the application of mathematics is not enough. The current Calculus textbook attaches great importance to the preciseness of the theory. The teaching content and system of calculus have basically followed the relatively stable and inherent model formed in the past for a long time in order to impart the basic concepts. The basic theory and method are the main purpose. This teaching mode leads to the disconnection between the teacher's teaching and the student's study. From the level of content development, most of them still follow the traditional concept definition From the theorem to the conclusion of the fixed pattern of examples. In the teaching process, pay attention to strict logical reasoning and problem-solving skills, What ignores the essence of calculus education should be intuitionistic and visualized. Theoretical teaching introduces the lack of practical background. The students' thinking in class is always guided towards a fixed direction step by step. It often pays attention to the theoretical knowledge and neglects its practical background and application value. 
The current teaching methods of calculus are backward. From the perspective of teaching methods, most of the current teaching methods of calculus are still abstract and obsolete because of the rigorous consideration of theory and knowledge system. The lectures often pay too much attention to the systematic teaching of knowledge, emphasizing the training of symbolic calculus and problem-solving skills, and neglecting the guidance from the aspects of intuition and problem background. The traditional teaching method and question answering method have been used all the time. Teachers seldom measure how much calculus knowledge students really understand and master. There is also little thought about how to use the least number of languages and the latest teaching techniques and means to inspire students' ability to learn and think autonomously, often using a single test score to measure students' learning effectiveness and achievement. Not paying attention to the students' learning process and assessing students' cognitive ability, lacking of experimental courses, students' difficulties in applying mathematics, lack of confirmatory experiments with calculus, computational experiments, Exploratory experiments and comprehensive design experiments. In this way of teaching, students only passively accept knowledge and find it difficult to give full play to their learning initiative. Flexibility, creativity and low learning efficiency are the common problems in the teaching of calculus in colleges and universities.

\section{The thinking about the Reform of Calculus Teaching}

\section{Principles of Teaching Reform}

For college students, learning calculus is just to enable them to further master the analytical and computational abilities of calculus on the premise of having a basic knowledge system of mathematics. To be able to have certain logical thinking ability. In the teaching reform of calculus, we should stick to the principle of unity, that is, to grasp the position of calculus in the whole study stage of the students, and the relationship between calculus and other subjects. In teaching, we should combine theory with practice, communicate with other subjects, infiltrate and cooperate with each other. The principle of visualization is to visualize and visualize abstract theoretical reasoning knowledge in the teaching process as far as possible. And appropriate addition of some simple mathematical modeling test questions, to increase students' interest in learning.

Selection of Teaching Content

In the teaching of calculus, the students themselves have a weak foundation in high school mathematics, but the teaching content of calculus is various, but the design of class hours is less. So we have to choose the teaching content of calculus. Because the senior high school mathematics knowledge of college students is not firm, we first review and consolidate it, review those knowledge plates that are related to calculus. In addition, contact students' major. The content of calculus teaching is divided into two modules, one is the general module, that is, the basic content that must be learned regardless of the major, the other is the special module, that is, combining the students' major, the content of different major learning is different. It can be used for its related professional courses in the future. It can add the content of mathematical modeling, that is, combine with the actual social problems, transform to solve with mathematical model, in order to improve the students' interest in learning, also can let the students understand the beauty of mathematics more deeply.

Improvement of the Teaching Model

People's understanding always starts with concrete, image, intuition, appearance, and then goes up to theory through practice. Teachers should add some practical phenomena and problems in the teaching process, so that students can discuss in groups. In practice, we think we can supplement some case teaching, discussion teaching, exercise self-help teaching and so on. For example, the application of derivative, the analysis of demand price elasticity, etc. The inventory management problem, the conditional extreme value problem of multivariate function, can introduce appropriate case, let the student combine the actual problem, abstract the problem to be solved. Finally, we use the calculus method to solve these practical problems. About the relation and relation between some concepts, it is more suitable for discussion teaching, such as the differentiability of multivariate 
function, the relation between continuity and partial derivative, so that we can participate in the discussion.

Developing Mathematical Modeling Teaching about Calculus

In the teaching of calculus, it is a beneficial attempt of teaching reform to integrate the thought and method of mathematical modeling into the teaching system, and it is an effective way to guide students to use the theory and method of calculus to solve the practical problems in economy. In teaching, economic problems should be closely linked to social and economic realities, and economic cases should be rationally cut into economic cases, so as to increase the teaching of typical economic application cases. For example, when we talk about limits, we can introduce continuous complex interest rates and derivatives. We can introduce the maximum profit and profit, etc. By using the thought method of mathematical modeling, we can thoroughly analyze and explain the typical economic cases, so as to arouse the students to think deeply and make them master the essence of mathematical modeling gradually. To cultivate students' consciousness of interpreting economic problems with mathematical modeling method, and to train students' ability to apply mathematical knowledge to solve economic problems.

\section{Strategies to Improve the Teaching quality of Calculus.}

People's understanding always starts with concrete, image, intuition, appearance, and then goes up to theory through practice. Teachers should add some practical phenomena and problems in the teaching process, so that students can discuss in groups. In practice, we think we can supplement some case teaching, discussion teaching, exercise self-help teaching and so on. For example, the application of derivative, the analysis of demand price elasticity, etc. The inventory management problem, the conditional extreme value problem of multivariate function, can introduce appropriate case, let the student combine the actual problem, abstract the problem to be solved. Finally, we use the calculus method to solve these practical problems. As to the relationship and relation between some concepts, it is more suitable for discussion teaching, for example, the differentiability of multivariate functions, the relationship between continuity and partial derivation is suitable for everyone to participate in the discussion. We are impressed by the structure of the relationship between the three. For example, we should let the students solve the problems in their homework independently. And in the process, we should add some common and simple mathematical software. As a result, students will also have a certain mathematical thinking mode. Although the students do not learn much mathematics knowledge, but students can have a certain ability of self-solving problems.

\section{Conclusions}

With the college entrance examination system reform is at the same time, the teaching content of calculus to decentralization, which for the teaching of calculus is a promotion, in addition, in the teaching of calculus is also in constant reform, believe that the quality of teaching calculus will rise to a higher level. In the reform, according to the particularity of calculus, re construction calculus is the new curriculum structure, handle the division and synthesis, sustained and balanced relations, need to deal with the relationship between the demand of modern society, discipline development and the needs of the students. In addition, the teaching methods should focus on the pursuit of intuitive, mathematics interest case introduction method and calculus thought enlightenment, the introduction of modern teaching means.

Both the choice of teaching content and the improvement of teaching means for calculus teaching is to prepare for the establishment of "three-dimensional teaching material", that is, on the basis of high-quality paper teaching materials. Then according to the development of calculus itself, the characteristics of the teaching object and its professional needs and research trends at home and abroad, the first is to combine the multimedia information to optimize and integrate the teaching content, and to improve the level of making multimedia courseware and teaching effect; The second is to improve the teaching system of calculus course by using relevant mathematics software. 


\section{Acknowledgments}

This research was supported by special subject of educational informatization of Higher Education Society in China (Grant No. 2016XXYB22).

\section{References}

[1] Acevedo Nistal, A., Van Dooren, W., Clarebout, G., Elen, J. \& Verschaffel, L.. Conceptualising, investigating, and stimulating representational flexibility in mathematical problem solving and learning: A critical review. ZDM Mathematics Education, 41(5)(2009) 627-636.

[2] Ainsworth, S. DeFT: A conceptual framework for considering learning with MR. Learning and Instruction, 16(3) (2006), 183-198.

[3] Bell, A. \& Janvier, C. The interpretation of graphs representing situations. For the Learning of Mathematics, 2(1) (1981), 34-42.

[4] Dreyfus, T. Advanced mathematical thinking. In P. Nesher \& J. Kilpatrick (Eds.), Mathematics and cognition: A research synthesis by the international group for the psychology of mathematics education, Cambridge University Press, United Kingdom,1990, pp. 113-134.

[5] Bossé, M. J., Adu-Gyamfi, K. \& Cheetham, M. R. Assessing the difficulty of mathematical translations: Synthesizing the literature and novel findings. International Electronic Journal for Mathematics Education, 6(3) (2011), 113-133.

[6] De Bock, D., van Dooren, W. \& Verschaffel, L. Students' understanding of proportional, inverse proportional, and affine functions: Two studies on the role of external representations. International Journal of Science and Mathematics Education, 13(1), (2015), 47-69.

[7] Jeffrey, R.C: Probability and the Art of Judgment, Cambridge University Press, United Kingdom,1992, pp.75-80. 